\title{
Monitoring pesticides residues in water resources of the Lake Naivasha catchment using passive sampling
}

\author{
Yasser Abbasi' ${ }^{1}$, Chris M. Mannaerts ${ }^{1}$ \\ ${ }^{1}$ Department of Water Resources, Faculty of Geo-Information Science and Earth Observation, University of Twente \\ Enschede, Netherlands \\ y.abbasi@utwente.nl; c.m.m.mannaerts@utwente.nl
}

\begin{abstract}
Passive samplers are able to recover the detection of low concentrations using continuous gathering the pollutants. While these contaminants might be undetected with the conventional grab sampling which is an once-off time-point sampling. In this study, Silicone rubber sheet samplers were used as the passive sampler to monitor the residue of some organochlorine pesticides, notably; $\alpha-\mathrm{HCH}, \beta-\mathrm{HCH}, \gamma-\mathrm{HCH}, \delta$-HCH, Heptachlor, Aldrin, Heptachlor Epoxide, pp-DDE, Endrin, Dieldrin, $\alpha$-endosulfan, $\beta$-endosulfan, pp-DDD, Endrin aldehyde, pp-DDT, Endosulfan Sulphate and Methoxychlor in the Lake Naivasha basin, Kenya. The samplers were deployed in the water for one month after which the concentration of the pesticides was measured by analyzing the extraction of samplers using the GC-ECD. Determining the organochlorine pesticides residues by means of the Silicone rubber samplers demonstrated that the maximum contamination occurred at the lake site with the total sum concentration of $81 \mathrm{ng} / \mathrm{L}$ which is the final accumulation location for surficial hydrological, chemical and sediment transport through the river basin. The total organochlorine residue changed to 71.5ng/L for the Middle Malewa and 59ng/L for the Upper Malewa river sampling sites. Finally, comparing the concentration of the studied pesticides with the maximum standard limit showed that the concentrations were below the limit. However, because of the risk of these pesticides continued monitoring of pesticides residues in the catchment remains highly recommended.
\end{abstract}

Keywords: Passive sampler, Silicone rubber sheet, Organochlorine pesticides, Contamination, Standard limit.

\section{Introduction}

Pollutants of the aquatic environments are usually monitoring using grab samples that are collected during a short time period. This conventional method of sampling can only provide a snapshot of contamination levels [1], [2] which is mostly linked to logistical and practical troubles containing transportation, purification, extraction, and storage [3]. In contrast, passive samplers accumulate the contaminants, making it potential to measure very low content of pollutants. Passive sampling provides allows continuous water quality monitoring that could be a short to long term (a week to some months) by which defining time-weighted average (TWA) of pollutant content would be possible [4]. The difference of chemical potential between passive sampler media and the pollutants in water makes a partitioning of contaminants between water and the sampler [5]. These properties of passive sampling simplify pollutants investigation in surface and groundwater that provides an alternative method to biomonitoring [6]-[9].

There are numerous types of passive samplers, which have been applied to explore the contaminants in aquatic environments [10]. Silicone Rubber (SR) passive samplers were used in this study for measuring organochlorine pesticides residues since Silicone Rubber samplers for hydrophobic compounds have some features such as simple construction, strong for deploying in the rivers or the lake, inexpensive and ordinarily accessible. These passive samplers hold the contaminants in a kinetic or equilibrium diffusion by which all of the procedures containing selective analyte, isolation and pre-concentration happens simultaneously [2].

Although there has been a decrease in organochlorine pesticide imports into Kenya, there is still a risk of using these pesticides against pests. The Lake Naivasha catchment is an important agricultural areas in which dense crop cultivation and high population have caused increase pesticides demand. The purpose of this study was monitoring the organochlorine pesticide residues contamination in the Lake Naivasha and Malewa river by means of passive sampling method.

\section{Methodology}

Lake Naivasha catchment has an area of about 3,400 km2 which is located in the eastern part of the Rift Valley region in Kenya. The main input to the Lake Naivasha is Malewa river that accounts for approximately $80 \%$ of the inflow into the Lake. At the sampling sites containing Upper Malewa, Middle Malewa river and the lake (Fig. 1), three sets of 
Silicon rubber (SR) sheet samplers were installed for monitoring Organochlorine pesticides (OCPs) of $\alpha-\mathrm{HCH}, \beta-$ $\mathrm{HCH}, \gamma-\mathrm{HCH}, \delta-\mathrm{HCH}$, Heptachlor, Aldrin, Heptachlor Epoxide, pp-DDE, Endrin, Dieldrin, $\alpha$-endosulfan, $\beta$ endosulfan, pp-DDD, Endrin aldehyde, pp-DDT, Endosulfan Sulphate and Methoxychlor. The guidelines for passive sampling of hydrophobic contaminants in water using silicone rubber samplers [11] were followed. Before installation, the SR samplers were pre-cleaned in Soxhlet apparatus with ethyl acetate for at least 100h to remove all chains of oligomers. Then they were air dried and spiked with six Performance Reference Compounds (PRCs) that had a sampler-water partition coefficient $(\log \mathrm{Kpw})$ between 3.5-5.5 as well as a PRC that is rarely depleted $(\log K p w>6)$ and a completely depleted PRC $(\operatorname{logKpw}<3.3)$. The amounts of PRCs fraction that remains in the samplers after deployment indicates sampling rate.

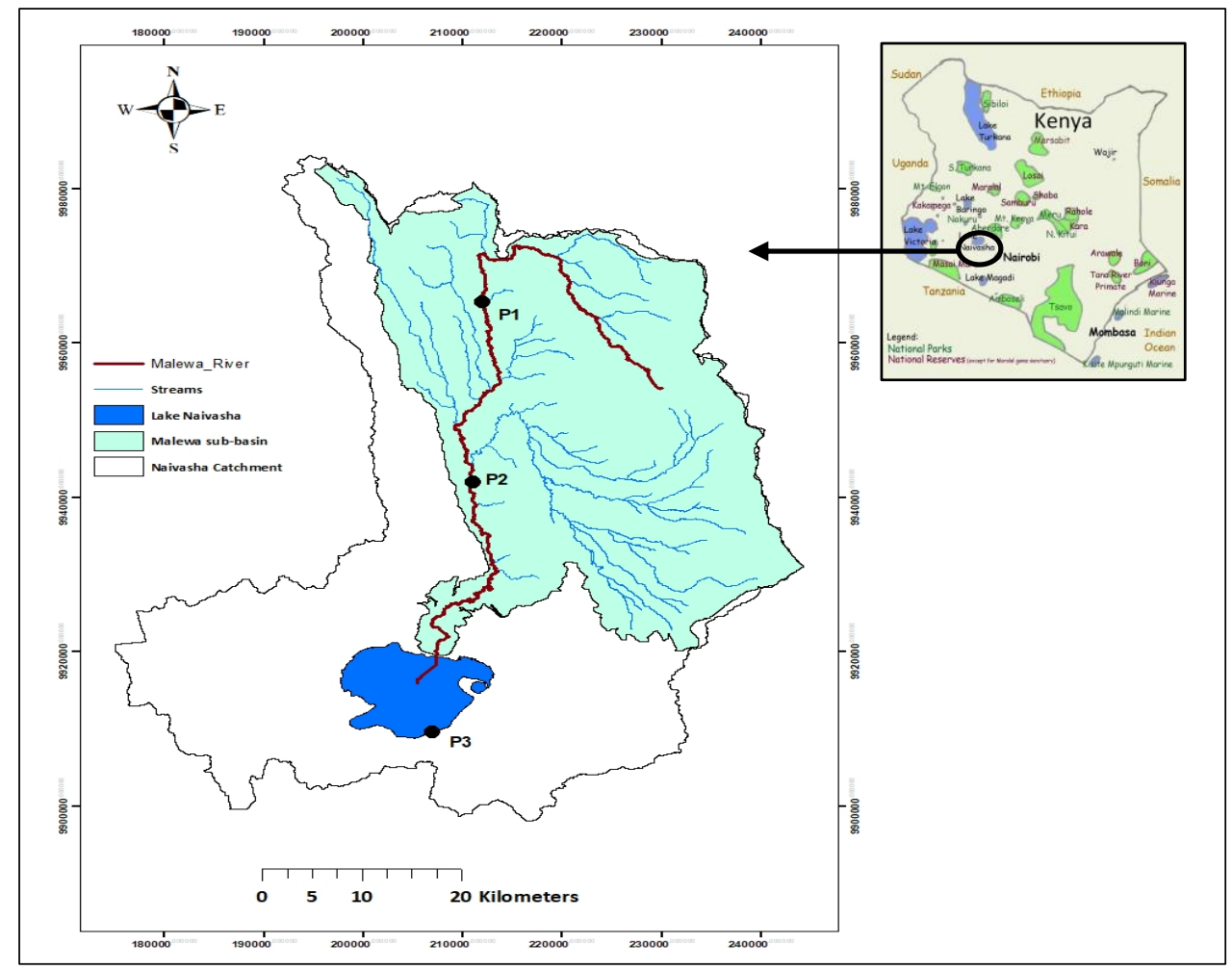

Fig. 1: Locations of passive samplers (P1, P2 and P3 are Upper Malewa, Middle Malewa and the Lake sites, respectively).

The samples were collected from the sampling sites after one month deployment then all of the procedures such as samplers extraction, clean up, concentrating and instrumental analysis were done according to the standard laboratory methods. The extracted pesticides residues and the PRCs were determined using a gas chromatograph (Agilent $6890 \mathrm{~N}$ ) in combination with an electron capture detector (Agilent $\mu \mathrm{ECD}$ ) and a GC-MSMS respectively.

The amounts of PRCs fraction $\left(f_{\text {exp }}\right)$ was estimated as:

$$
f_{\text {exp }}=\frac{N_{t}}{N_{0}}
$$

where $N_{t}$ and $N_{0}$ are PRCs amounts (ng) in the exposed and the reference samplers, respectively. PRCs fraction $(f)$ is a function of $\mathrm{K}_{\mathrm{pw}}$ and the sampling rate $\left(R_{S}\right)$ :

$$
f_{c a l}=e^{\frac{-R_{s} t}{K_{p w} m}}
$$

where $R_{S}$ is calculated as below:

$$
R_{s}=\frac{F A}{M^{0.47}}
$$


Finally, the amount of the residues in the samplers $\left(N_{t}\right)$ and in the aquatic environment $C_{w}$ were calculated as follow:

$$
\begin{gathered}
N_{t}=C_{w} \cdot K_{p w} m\left[1-\exp \left(\frac{-R_{s} t}{K_{p w} m}\right)\right] \\
C_{w}=\frac{N_{t}}{K_{p w} m\left[1-\exp \left(-\frac{F A t}{M^{0.47} K_{p w} m}\right)\right]}
\end{gathered}
$$

where $K_{p w}$ is the sampler-water partition coefficient $(\mathrm{L} / \mathrm{kg}), m$ is the sampler weight $(\mathrm{kg}), t$ is the exposure time (days) and $R_{S}$ is the sampling rate (L/day) which is a function of the hydrodynamic situation and the sampler surface area $(F A)$ as well as the PRC molar mass $(\mathrm{M})$.

\section{Results and Discussion}

The outcomes revealed the least sampling rate in the in Lake Naivasha with $1.9( \pm 0.4 \mathrm{SD}) \mathrm{L} /$ day and the highest rate at the Middle Malewa river site with 13.1L/day. The sampling rate at the Upper Malewa river site was 6.2L/day, that could be average rate compared to other sites. comparing the results of this study with the study by Harman et al. (2009) showed these results were comparable to their finding. They reported sampling rates between 4.1 and $14.8 \mathrm{~L} /$ day for a duration of 6 weeks. Moreover, calculation of the PRCs fraction also showed that there was a harmony between the measured and calculated fractions (Fig. 2).
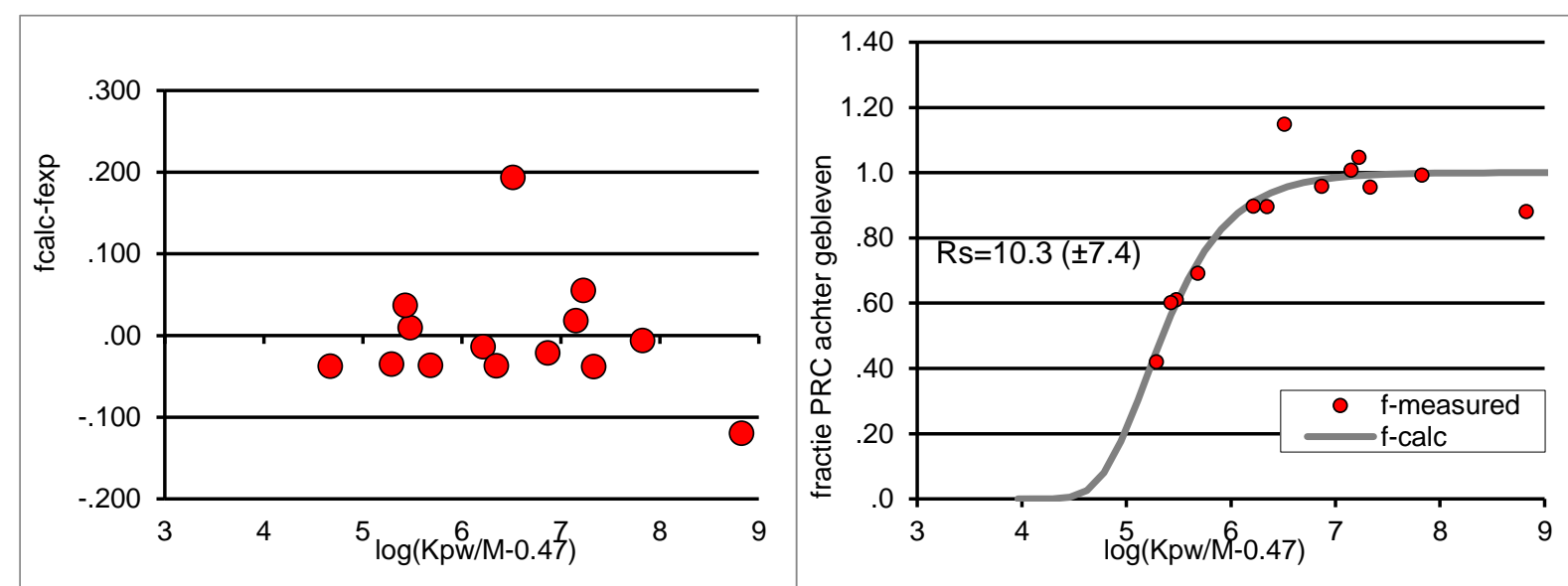

Fig. 2: Example diagram of logKpw versus Retained PRC fractions (right) and difference of calculated and measured (calc.) (left).

Calculating the OCPs residues concentrations in the SR sampler demonstrated that the total amount of $\alpha-\mathrm{HCH}, \beta$ $\mathrm{HCH}, \gamma-\mathrm{HCH}, \delta-\mathrm{HCH}$, Heptachlor, Aldrin, Isodrin, Heptachlor Epoxide, $\alpha$-endosulfan, pp-DDE, Endrin, Dieldrin, $\beta$ Endosulfan, pp-DDD, Endrin aldehyde, pp-DDT, Endosulfan Sulphate and Methoxychlor highest amount at the lake site with a total amount of $81 \mathrm{ng} / \mathrm{L}$. This amount decreased to $71.5 \mathrm{ng} / \mathrm{L}$ and $59 \mathrm{ng} / \mathrm{L}$ at the Middle Malewa and the Upper Malewa river sites, respectively. Based on the results of SR samplers, Endosulfan Sulphate had the most concentration in the study area with the values of $56 \mathrm{ng} / \mathrm{L}, 39.3 \mathrm{ng} / \mathrm{L}$ and $34.2 \mathrm{ng} / \mathrm{L}$ in the Lake Naivasha, Middle Malewa river and Upper Malewa river sites. The second major pesticide found at the sampling sites was $\alpha-\mathrm{HCH}$. The concentration of this pollutant varied from 19.3ng/L at the Middle Malewa river site to the amount of $11.3 \mathrm{ng} / \mathrm{L}$ at the Lake site. Methoxychlor was also found in the SR samplers at all sampling sites. Other pesticides had a very low concentration.

Comparing the spatial distribution of the studied pesticides demonstrated that although there was an growing amount of OCPs from the Upper Malewa to the Lake, the results of one-way ANOVA analysis for the means of the three sampling sites confirmed that there was not a meaningful spatial differences $(\mathrm{P}>0.05)$. Regardless of pesticides application in the downstream of the studied area, the higher magnitude of OCPs at lake site could be related to this fact that the hydrological stream flow and suspended sediment can transport agrochemical from the upper part of the catchment to the down part. This issue can cause the concentration gradient and consequently accumulation of pesticides in the lake.

Finally, comparing the pollution levels of pesticides in the water for different sampling sites with the drinking water standards criteria [13] showed that the concentrations of all the studied pesticides were below the WHO drinking water standard and limits. This finding could confirm that the environmental risk in the studied area is still safe. However, 
because of the high toxicity of OCPs and their effect in environment, continues monitoring of them is still highly recommended.

\section{Conclusion}

This study examined OCPs residues in surface water resources of the lake Naivasha catchment, using passive sampling techniques. OCPs residue concentrations analysis revealed that $\sum$ OCPs had the highest value at the Lake site. This can be probably explained by the fact that the lake is the ultimate accumulation site of streamflow, suspended sediment and agrochemicals that are mobilised in the catchment. The $\sum$ OCPs for the Middle Malewa and the Upper Malewa river sites were the second and third amounts, respectively. Finally, it can be concluded that exploration of OCPs using passive sampling is a very useful method that can contribute to aquatic environment monitoring and pollution studies in tropical catchments.

\section{References}

[1] M. D. Hernando, D. Lambropulou, I. Konstantinou, M.J. Martinez Bueno, D. Gabrielides, A.R. FernandezAlba and T. Albanis, "Passive sampling techniques for monitoring organic contaminants in aquaculture environment," in Proceedings of the 10th International Conference on Environmental Science and Technology, Cos Island, Greece, 2007, September, pp. B276-B283.

[2] B. Vrana, I. J. Allan, R. Greenwood, G. a. Mills, E. Dominiak, K. Svensson, "Passive sampling techniques for monitoring pollutants in water," TrAC - Trends Anal. Chem., vol. 24, no. 10, pp. 845-868, 2005.

[3] Y. Abbasi and C. M. Mannaerts, "Evaluating organochlorine pesticide residues in the aquatic environment of the Lake Naivasha River basin using passive sampling techniques," Environmental Monitoring and Assessment, vol. 190, no. 6, 2018.

[4] L. Ahrens, A. Daneshvar, A. E. Lau, and J. Kreuger, "Characterization of five passive sampling devices for monitoring of pesticides in water," J. Chromatogr. A., vol. 1405, pp. 1-11, 2015.

[5] I. J. Allan, K. Booij, A. Paschke, B. Vrana, G. A. Mills, and R. Greenwood, "Field performance of seven passive sampling devices for monitoring of hydrophobic substances," Environ. Sci. Technol., vol. 43, no. 14, pp. 538390, 2009.

[6] I. Munoz, M. J. Martinez Bueno, A. Aguera, and A. R. Fernandez-Alba, "Environmental and human health risk assessment of organic micro-pollutants occurring in a Spanish marine fish farm," Environ. Pollut., vol. 158, no. 5, pp. 1809-1816, 2010.

[7] A. Meyn, P. S. White, C. Buhk, and A. Jentsch, "Environmental drivers of large, infrequent wildfires: the emerging conceptual model," Prog. Phys. Geogr., vol. 31, no. 3, pp. 287-312, 2007.

[8] K. Wille, M. Claessens, K. Rappé, E. Monteyne, C. R. Janssen, H. F. De Brabander, L. Vanhaecke, "Rapid quantification of pharmaceuticals and pesticides in passive samplers using ultra high performance liquid chromatography coupled to high resolution mass spectrometry," J. Chromatogr. A., vol. 1218, no. 51, pp. 9162 9173, 2011.

[9] J. T. Fox, G. Adams, M. Sharum, and K. L. Steelman, "Passive sampling of bioavailable organic chemicals in Perry County, Missouri cave streams," Environ. Sci. Technol., vol. 44, no. 23, pp. 8835-8841, 2010.

[10] B. Brockmeyer, U. R. Kraus, and N. Theobald, "Accelerated solvent extraction (ASE) for purification and extraction of silicone passive samplers used for the monitoring of organic pollutants," Environ. Sci. Pollut. Res., 2015.

[11] F. Smedes and K. Booij, "Guidelines for passive sampling of hydrophobic contaminants in water using silicone rubber samplers," 2012.

[12] C. Harman, K. V. Thomas, K. E. Tollefsen, S. Meier, O. Bøyum, and M. Grung, "Monitoring the freely dissolved concentrations of polycyclic aromatic hydrocarbons (PAH) and alkylphenols (AP) around a Norwegian oil platform by holistic passive sampling," Mar. Pollut. Bull., vol. 58, no. 11, pp. 1671-1679, 2009.

[13] WHO, "WHO guidelines for drinking-water quality.," WHO Chron., no. Fourth Edition, 2011. 